\title{
PECULIARITIES OF THE GENDER CULTURE OF UKRAINE: VERIFICATION OF THE SOCIO-SYSTEMOLOGICAL APPROACH (ACCORDING TO THE RESULTS OF THE AUTHOR'S EMPIRICAL RESEARCH)
}

\author{
Yuriy Romanenko \\ Doctor of Sociology, Professor at the Department of International Media Communications \\ and Communication Technologies, Institute of International Relations, \\ Taras Shevchenko National University of Kyiv, Ukraine \\ e-mail: romanenko.jura@gmail.com,orcid.org/0000-0001-6395-4395
}

\author{
Ivan Svyatnenko \\ Candidate of Sociological Sciences, Ukraine \\ e-mail: magellan4x4@ukr.net, orcid.org/0008-0006-5896-6273
}

\section{Summary}

The aim of the article is the cultural and socio-systemological interpretation of the results of empirical research of gender culture in Ukraine. Generalization of the empirical data obtained by the author made it possible to formulate the following conclusions. The ideologies of matriarchal racism and sexism value the inferiority of men's life and health, property rights, freedom of selfactualization, opportunities for raising children, and so on. At the micro level of socio-institutional relations (matriarchal family) due to these areas of value consciousness there is a recursion of gender ideology in the form of gender morality, which reflects the neofunctionalist (cultural and socio-systemic) interpretation of the mechanisms of autopoiesis of the cultural system.

The matrimonial nuclear family in the conditions of Ukrainian gender culture acquires a dyadic form, ie, the classical triad scheme of relations in the family (father-mother-child) is replaced by a dyadic due to the scenario of peripherization-displacement of the man outside the family space and positioning him as a sub of service activities to ensure consumer projects of mother and child.

In gender morality, the recursion of matriarchal racism and sexism takes the form of matriarchal familiarism. In the gender consciousness, matriarchal familiarism means the implicit recognition of a woman and a child as a self-sufficient dyad, in which the man is not so much a selfsufficient subject as an instrument of financial, property, labor and other instrumental resources.

Keywords: gender culture, gender culture of Ukraine, cultural and socio-systemic model, feminolatry, double gender standards, homophobia, heterophobia, gender features of value hierarchies.

DOI https://doi.org/10.23856/3914

\section{Introduction}

In Ukrainian society, the phenomena of gender inequality are widespread, which in everyday life are disguised as their opposite, that is, gender equality and the corresponding ideology of apparent egalitarianism. Both men and women are guided by double gender standards and scenarios, which is reflected in the destructive social behaviors of both sexes. These standards and scenarios are partly enshrined in current Ukrainian legislation (legal norms), partly represented in moral norms (norms of social morality).

The problem of empirical research is the contradiction between the scientific assessments of Ukrainian gender culture as patriarchal (biarhatic) and its actual matriarchal-sexist 
content. This contradiction results in a distorted assessment of the state of gender relations and needs to be resolved by enlightening the relevant empirical manifestations of genicocratic gender racism, matriarchal sexism and androcidal orientation of gender behavior scenarios, the implementation of which creates preconditions for reducing the quality of life and population (Svyatnenko, 2018: 195 - 202).

The aim of the article is the cultural and socio-systemological interpretation of the results of empirical research of gender culture in Ukraine.

An analysis of recent research and publications in which the scientific problem was initiated presented both in the publications of the author and Romanenko Yu.V., whose research is devoted to the problems of cultural and social systemology and is focused on clarifying the axiospheric, social-stratification and social-institutional determinants of the gender culture of Ukraine (Svyatnenko, 2018: 52-61; Svyatnenko, 2019: 85-94; Svyatnenko, 2019: 65-73; Svyatnenko, 2019: 35-44; Etnycheskaia ydentychnost, 2016:140-220; Svyatnenko, 2018:195-202; Svyatnenko, 2019: 102-109).

\section{On matriarchal racism, sexism, genocide and feminolatry}

Matriarchal racism, sexism, genocide and feminolatry are part of the everyday social ideas of both men and women. At the level of gender perceptions of both female and male respondents, stereotypes of matriarchal racism, sexism, feminolatry, sacralization of femininity, and the priority of genicocracy over masculinocracy prevail.

To the indicative question about the consent / disagreement of respondents with the attribution to women of creative functions in the universe, life-preserving potentials in the family, generative, spiritual and competence advantages of women over men, the arithmetic majority of those who agree with the attribution of these functions and features was , 2 and $69.4 \%$ of men and women, respectively) and minority of dissenting respondents (23.8 and $18.6 \%$ of men and women) (Svyatnenko, 2018: 52-61).

\section{Maternal-matrix and matriarchal-racist stereotypes}

Maternal-matrix and matriarchal-racist stereotypes about the primacy, superiority, and superiority of women over masculinity are shared by the majority of both men and women. About half of men $(48.2 \%)$ and almost $80 \%$ of women $(78.8 \%)$ share the view on the correctness of maternal and matriarchal-racist judgments about the need for women to reproduce, their superiority over men in spiritual and moral terms, which allows to verify hypothesis about the predominance among the female subgroup of the sample, compared with the male subgroup of the sample, the number of supporters of stereotypes of matriarchal racism, sexism, feminolatry, the sacralization of femininity, the priority of genicocracy over masculinocracy.

Significantly higher competence of women, compared to men, in mental problems recognized 58.2 and $79.0 \%$ of men and women, respectively, the spiritual superiority of women over men -44.6 and $61.2 \%$ of men and women, respectively, which verified the hypothesis of perfectionist moral ideas about a woman as the Creator-creator of the world, guardian, as well as the identification of her image with the implementation of educational, psycho- and socio-therapeutic roles (educator, psychotherapist-healer, mentor, mentor, tutor, etc.). It was determined that $15.8 \%$ of women and $23.6 \%$ of men are supporters of masculinity in gender relations, while the number of supporters of gynecocracy among both men and women are significantly higher (35.4\% and 53.2\%, respectively) (Svyatnenko, 2018: 52-61). 
A theoretical generalization is formulated, according to which a larger number of female respondents more realistically, in comparison with male respondents, evaluate the gynecocracy present in the models of relations. It was found and stated that male respondents are more likely not to recognize the existing gender inequality and gender privileges in the relationship, as indicated by the discrepancy between female and male subgroups by almost $15 \%$ in assessing the actual scenario of gender hierarchy.

An empirical pattern of non-acceptance by the arithmetic majority of men in Ukraine of patriarchal dominance as a model of family life has been established and stated. In support of this, the empirical study found that victimization and egalitarian gender models are chosen by $35.4 \%$ and $41 \%$ of male respondents, with a significant minority of men who choose the scenario of patriarchal dominance $(23.6 \%)$. Despite the presence of $41 \%$ of male respondents as supporters of the egalitarian model of gender relations, it is emphasized that it is declarative and fictitious due to the circumstances of socio-moral stereotypes and legal restrictions.

\section{Double gender standards}

Theoretically generalized provisions on double standards in the assessment of psychosexual deviations by men and women by men and women in the presence of aggressive attitude to these deviations in their demonstration by men by men and women and natural / ignorant attitude in the demonstration of the same deviations by women by men and women. In support of this theoretical position, it is empirically established and proven that in assessing the homoerotic behavior of young women in public, respondents of both sexes (men and women) show almost the same number of ignorance reactions (70 and $73 \%$, respectively). The differences between men and women in the application of conditional moral sanctions are insignificant: $31.4 \%$ for young men by respondents of both sexes and $29.7 \%$ for young women by respondents of both sexes (Svyatnenko, 2019: 85-94).

Additionally, the theoretical generalization on double gender standards for estimating the deviations of men and women is empirically verified by the statement of quantitative advantages in the use of expressive forms of moral and ethical repression among respondents of both sexes on young men. For young women, the tactics of loud indignation and reading the notation on the inadmissibility of homoerotic behavior would be implemented by $10.2 \%$ of respondents of both sexes, while for men it would be done by $33.2 \%$ of respondents.

This allowed us to verify the hypothesis that in the assessment of deviant erotic and sexual behavior in men and women there are two gender standards: intolerant / repressive standards in assessing erotic and sexual behavior of men and tolerant / ignorant (analogical) deviant behavior of women. A theoretical generalization is made regarding the demonstration by respondents of both articles of double standards in the application of additional measures of public pressure on young men in comparison with young women.

This generalization is empirically verified by the data of the virtual situation on the manifestations of homoerotic behavior of young women in a public place, in which only $7.6 \%$ of respondents of both sexes showed willingness to pay attention to other participants in the public situation (for example, other public transport passengers). while for young men, the number of potentially ready to read notation with elements of emotional outrage, and to include public pressure, increases 10 times (up to $71.4 \%$ ).

In reviewing the moral and ethical grounds chosen by respondents to justify certain manifestations of verbal and physical aggression against homoerotic behavior of young men and women, it was determined that $30 \%$ of respondents of both sexes believe that homoerotic 
behavior of both sexes is quite normal and admissible, $70 \%$ of respondents of all ages consider such behavior unacceptable, due to residual stereotypes of Soviet sexual morality, which implies only a hidden realization of sexuality and legitimizes the meticulous attitude to the manifestations of erotic behavior in public places by young people (Svyatnenko, 2018: 52-61).

On the other hand, the explanation of the fact of negative assessment of erotic and sexual behavior can be explained by the existing in traditional Ukrainian culture attitudes to shyness, secrecy / latency, generating dissatisfaction with the older generation of youth in the context of sexuality and eroticism (Svyatnenko, 2018: 52-61).

At the same time, the evaluation of Soviet quasi-Puritanism - the ideology and morality of the ephemeral "liberation" of the Soviet man from sexual fantasies, desires, inclinations, etc. in the experience of youth and the older generation and its combination with the ideology and morals of matriarchal racism and sexism.

An additional theoretical position is formulated, according to which the ideology and morality of matriarchal racism and sexism substantiates and assumes higher repressive and restrictive tendencies of women (compared to men) to regulate the physical behavior of men, structuring their physical and physical environment and imposing appropriate regimes on them. needs than similar tendencies on the part of men towards women.

This theoretical position is confirmed by empirical research, according to which $20 \%$ of men and $22 \%$ of women consider it necessary to criminalize the assumption of homoerotic behavior of men in relation to each other, while the criminalization of such behavior for women approves only $2 \%$ of male respondents and 1\% of women (Svyatnenko, 2018: 52-61).

\section{Asymmetry of gender-based violence and restriction of horizontal communication of men after marriage}

Provisions have been formulated for men to tolerate physical violence against women against themselves and double standards for assessing the need to continue premarital friendly (friendly) communication between men and women.

To empirically verify this provision, the attitude of respondents of both sexes to the assessment of possible physical violence of men against women and women to men was characterized and the hypothesis was verified that men will treat women's physical violence more tolerantly and will be more restrained in assessing women's violence against themselves. women. It was stated that women are expected to assess male aggression as immoral in a higher percentage of cases than vice versa. It was stated that the vast majority of men (64\%) are in the position of ethical tolerance of female violence, or justify physical aggression by women, citing its natural weakness.

On the other hand, only $10 \%$ of male respondents consider a woman's restraint on male aggression to be morally normalized, although $20 \%$ of male respondents still suggest physical violence. An empirical study verified the hypothesis that men's horizontal communications after marriage are more likely to be transformed in the direction of their full / partial blocking and limitation in space and time. This is confirmed by the fact that only $14 \%$ of female respondents consider it normal for men to maintain previous relationships with friends after marriage.

It is emphasized that more than half of female respondents $(61 \%)$ consider it necessary to terminate relations between male friends, limit their time or "allow" men to communicate only in the presence of women ("family communication" format). It was stated that only $25 \%$ of male respondents consider it necessary to terminate or limit premarital friendships between female friends. On the other hand, among male respondents the number of those who exceed the 
number of supporters of the invariability of friendly relations between women after marriage is $35 \%$, which is $20 \%$ more than the number of supporters of male friendship after marriage among the female part of the sample (Svyatnenko, 2019: 85-94).

\section{Gender tolerance / intolerance}

A theoretical position on gender tolerance / intolerance towards minority gender groups (gays, bisexuals, lesbians, prostitutes) has been formulated, which follows from multiple standards for assessing the socio-gender status of the respective minority community. The hierarchy of the respective communities reflects their place in the socio-gender stratification and attribution of the highest status to nominal heterosexuality, slightly lower to prostitutes, and the lowest status to lesbians, bisexuals, and gays.

This provision is formulated on the basis of the definition of comparative tolerance / intolerance. The highest rates of intolerance were found for gays, lesbians and bisexuals ( 52 and $54 \%, 54$ and $58 \%$ and 74 and 51\%, respectively, among men and women in the sample), the lowest - for prostitutes (21 and 35\%, respectively). Emphasis is placed on the more intolerant attitude of female respondents to prostitutes compared to male respondents, which is explained by the predominance of domestic and shadow prostitution in Ukraine over legal.

\section{Homophobia / heterophobia}

Based on the assessed indicators of heterophobia and attitudes towards same-sex communication on the part of men and women in the form of male and female friendship, demands for merger / separation of family members with each other, a theoretical position on gender identity inversion and double standards for friendly (friendly) relations as normative (relations between women) and deviant (relations between men). The stated position is confirmed by the fact that only $18 \%$ of male respondents show a heterophobic attitude towards female friendship.

The vast majority of male respondents $(53 \%)$ perceive the parallel communication of wives / girlfriends with their ex-girlfriends as normal and normal. On the other hand, only 7\% of female respondents believe that the situation of men's communication with friends (male friends) is quite acceptable and should not be interfered with in any way. The reactions of 69\% of female respondents, according to the study, are heterophobic, with $38 \%$ of women believing that male friendships have a homosexual connotation, and $21 \%$ willing to resort to indirect or direct pressure to block or interrupt such communications.

The formulated provision is supplemented by the statement that double standards of evaluation of friendly (friendly) relations between women as normative and relations between men as deviant block the processes of gender differentiation and segregation of men as a community (Svyatnenko, 2019: 85-94).

\section{Features of financial and property distribution in the matriarchal gender scenario}

Peculiarities of financial and property distribution as a part of matriarchal gender scenario are determined. It is determined that the majority of women and men $(69 \%)$ are inclined to the position of budget management by women on the basis of their higher (male) financial competence and better understanding of financial costs. It is noteworthy that only $32 \%$ of men and $26 \%$ of women consider the egalitarian (equal) scenario to be the most acceptable option for a financial management strategy. 
Based on this, a theoretical position is formulated, according to which the vast majority of respondents of both sexes are supporters of matriarchal racism and sexism in the organization of household finances, based on the a priori attribution of higher competence to women in finances and property compared to men. The theoretical position is supplemented by the statement that this attitude legitimizes the further exploitation of the husband by the matriarchal family, represented by the dyadic system of relations "child-mother" with the peripheralization of the father as a participant in family relations (Svyatnenko, 2019: 65-73).

\section{Genicocratic gender stereotypes}

Based on the high level of influence of genicocracy (women's power) identified in the empirical study, a list of gender stereotypes was formed among respondents, which is represented in the form of gender stereotypes of everyday consciousness: regarding peacekeeping and peace-loving women; moral superiority of women over men, de facto "gender equality" in Ukraine (in its absence); on the expert role of women in meeting the vital needs of men (clothing, nutrition, sex, etc.); on domestic and organizational helplessness of men in comparison with women; on women's secret knowledge of men (defined as a stereotype of "a priori wisdom" of women; on women's altruism (as opposed to male selfishness); on women's helplessness, insecurity and masculinity. From the results of the survey it is clear that from 63 to $85 \%$ Respondents of both sexes share the above stereotypes, which are derived from genicolatric and maternolatric social morality (Svyatnenko, 2018: 52-61).

\section{Gender features of value hierarchies of men and women}

The peculiarities of the value hierarchy of men and women are determined. It is stated that the male hierarchy of values is shifted to the vital-biological, professional-labor and career blocks, and the values of social prestige. It is emphasized that in women the second and third positions in the value hierarchy are occupied by dignitophilic values (freedom and creative self-actualization) and values associated with the accumulation of intellectual capital. It is noted that family values and values related to motherhood and childhood (well-being of women and children) are slightly higher for men than for women (rank deviation between male and female parts of the sample is 1.0 and 1.2, respectively) (Svyatnenko, 2019: 65-73).

It is determined that women, in comparison with men, define the value rank of career and professional activity as the highest (rank deviation between male and female parts of the sample is 0.9 , respectively), which indicates the career orientation of women, the predominance of vectors in their sample. creative self-actualization and freedom and tendencies to increase intellectual capital in comparison with men (Svyatnenko, 2019: 35-44).

\section{The ideal gender self}

Based on the analysis of gender features, it was determined that the image of the ideal gender "I" in men in autostereotype is dominated by volegalmic and emotional-communicative traits and physical attractiveness, which, in fact, brings male identity closer to the feminized-feminine pole. Among them, 34\% - courage, $12 \%$ - the ability to make friends, $10 \%$ - calmness and restraint, and $9 \%$ - restraint of aggression. It was stated that $2 / 3$ of these qualities on the rating scale correspond to the feminized autostereotype of men. It is stated that in the heterostereotype of women in the assessment of men $22 \%$ is 
femininity, $16 \%$ - warmth and cordiality, $15 \%(2 * 15)$ - flexibility, the ability to adapt to circumstances and a clear position.

It is emphasized that empathetic, adaptive and ego-autonomous features of gender identity in women by men are in demand. The autostereotype of women is dominated by love for children (18\%), the ability to empathize (16\%), tenderness $(13 \%)$, devotion $(11 \%)$ and the ability to help (10\%). It is summarized that the image of the ideal gender ego of women in their self-perception is mainly child-centered and empathetic. It is emphasized that with the predominance of child-centeredness in the number of choices in comparison with other gender qualities, there are grounds to conclude that the empathy, tenderness and devotion of women are redirected from men to children.

At the same time, respondents in the heterostereotype of men identify as significant traits calmness and restraint (18\%), limited use of abusive language (15\%), love for children, tendency to lead and courage $(3 * 12 \%)$, which illustrates the gender profile desirable for the female part of the sample features that also correspond to the image of a feminized man with volegalmic qualities and pronounced child-centeredness. It is emphasized that in the gender profile of men in the heterostereotype of women, the leadership qualities and courage of men occupy, compared to calmness / restraint and verbal limitations on obscene vocabulary, the last two places.

\section{Conclusions}

The ideologies of matriarchal racism and sexism value the inferiority of men's life and health, property rights, freedom of self-actualization, opportunities for raising children, and so on. At the micro level of socio-institutional relations (matriarchal family) due to these areas of value consciousness there is a recursion of gender ideology in the form of gender morality, which reflects the neofunctionalist (cultural and socio-systemic) interpretation of the mechanisms of autopoiesis of the cultural system.

The matrimonial nuclear family in the conditions of Ukrainian gender culture acquires a dyadic form, ie, the classical triad scheme of relations in the family (father-mother-child) is replaced by a dyadic due to the scenario of peripherization-displacement of the man outside the family space and positioning him as a sub of service activities to ensure consumer projects of mother and child.

In gender morality, the recursion of matriarchal racism and sexism takes the form of matriarchal familiarism. In the gender consciousness, matriarchal familiarism means the implicit recognition of a woman and a child as a self-sufficient dyad, in which the man is not so much a self-sufficient subject as an instrument of financial, property, labor and other instrumental resources.

The ideology and morality of matriarchal racism, sexism, feminolatry, the sacralization of femininity, the priority of genicocracy over masculinism is based on social ideas about the superiority of femininity and femininity as a gender group and a constituent component of social morality. This group of ideas corresponds to the implicit notions of the inferiority of masculinity and masculine origin, which creates the basis for matriarchal gender dominance and legitimization of women's gender privileges over masculinity through the matriarchal state.

Women's gender privileges over masculinity are objectively expressed: a) in social morality - at the level of unconscious attribution to women of a priori knowledge (life wisdom), spirituality, decency compared to men, social altruism, special competence in family relations, social communication, pedagogy, etc .; b) in the field of legal relations - in the form of gender-disparity regulations in certain areas of law and jurisprudence, which are indicative of women's gender privileges (these are regulations and practices in the field of family, social, criminal and criminal procedure, penitentiary, etc.); c) in attributing to women "regulatory 
competence" (at the level of moral stereotypes) in the field of biopolitics, in particular: on male corporeality in the segments of sexuality, structuring food behavior, organization of sanitary spaces, choice of clothing, etc.

Consolidation of these gender privileges is done by passification and objectification of men and justification (at the level of stereotypes of social morality) of the inevitability of female patronage over men. This enshrines the right of women to disciplinary penetration of women and the body-psyche of men, which should be considered as the primary form of gender micro-government in Ukrainian gender culture. Such gender micro-government allows women to apply the mechanisms of moral coercion of men in the premarital period and legal coercion - in the period after marriage. The latent implementation of women's patronage over men involves the spread of the mythology of women's self-sufficiency and men's lack of self-sufficiency, which becomes a factor of moral pressure on men to encourage them to marry.

\section{References}

Danilov, A. N., Rotman, D. G. (2019). Soft power priority in destabilizing contemporary socium (case of the Republic of Belarus) [Sotsiologicheskie Issledovaniya].January (2). [in English] Martynenko, M., Prytychenko, T., Gron, O., Us, M. (2019). Prospects for innovations in marketing of economic educational services in Ukraine [Entrepreneurship and Sustainability]. Issues, 6 (4). [in English]

Martsenyuk, T., Troian, I. (2018). Gender role scenarios of women's participation in Euromaidan protests in Ukraine [Crisis and Change in Post-Cold War Global Politics: Ukraine in a Comparative Perspective]. [in English]

Martsenyuk, T., Grytsenko, G., Kvit, A., Berlinska, M. (2018). Integration of women into the Armed Forces: Perspectives and problems of Ukrainian society [Laboratorium[ Russian : Review of Social Research. [in English]

Martsenyuk, T. (2015). Women's top-level political participation: Failures and hopes of Ukrainian gender politics [New Imaginaries: Youthful Reinvention of Ukraine's Cultural Paradigm]. [in English]

Svyatnenko, I. O. (2018). Henderna kultura Ukrainy: proekt prohramy empirychnoho doslidzhennia [Sotsialni tekhnolohii: aktualni problemy teorii ta praktyky] Zaporizhzhia: KPU. [in Ukrainian]

Svyatnenko, I. O. (2018). Ideolohiia ta moral hendernoi kultury v Ukraini [Hrani: naukovoteoretychnyi almanakh]. Dnipro: Hrani. [in Ukrainian]

Svyatnenko, I. (2019). Gender standards and expectations on sexual deviations in the gender culture of Ukraine [Hrani: naukovo-teoretychnyi almanakh]. Dnipro: Hrani. [in Ukrainian]

Svyatnenko, I. (2019). Gender xenophobia: candidate gender behavior in a love and preliminary period [Hrani : naukovo-teoretychnyi almanakh] Dnipro : Hrani. [in Ukrainian]

Svyatnenko, I. V. (2019). Determinants of financial-mine distribution, gender socialisation, gender-generation and genicocratia in gender culture of Ukraine [Sotsialni tekhnolohii: aktualni problemy teorii ta praktyky]. Zaporizhzhia : KPU. [in Ukrainian]

Svyatnenko, I. (2019). Reculiarities of valuable hierarchization and gender identities of men and women [Sotsialni tekhnolohii: aktualni problemy teorii ta praktyky]. Zaporizhzhia: KPU. [in Ukrainian]

Zoska, Ia.V., Medvedeva, Yu.Iu.,. Romanenko, Yu.V, Sviatnenko, Y.A., Tulenkov, N.V., Khomeryky, E.A. (2016). Etnycheskaia ydentychnost: sotsyosystemolohycheskoe yzmerenye heopolytyky [Monohrafyia]. K.: Merkiury-Podole. [In Russian]. 